\title{
Effect of lycopene on oxidative ovarian damage induced by cisplatin in rats
}

\author{
Nur G. Kulhan ${ }^{1}$, Mehmet Kulhan ${ }^{1}$, Can Turkler ${ }^{1}$, Nahit Ata $^{1}$, Tunay Kiremitli ${ }^{1}$, Sevil Kiremitli ${ }^{1}$, \\ Ferda Keskin Cimen ${ }^{2}$, Halis Suleyman ${ }^{3}$ and Veysel Toprak ${ }^{4}$ \\ ${ }^{1}$ Erzincan University Medical Faculty, Gynaecology and Obstetrics Department, Erzincan, Turkey \\ ${ }^{2}$ Erzincan University Medical Faculty, Medical Pathology, Erzincan, Turkey \\ ${ }^{3}$ Erzincan University Medical Faculty, Medical Pharmacology, Erzincan, Turkey \\ ${ }^{4}$ Lotus Hospital, Gynaecology and Obstetrics Department, Urfa, Turkey
}

\begin{abstract}
The anti-cancer drugs, particularly those used in reproductive period, may cause several complications such as ovarian insufficiency and infertility. The mechanism of action of cisplatin toxicity on the ovaries is not fully described. However, further production of free oxygen radicals and reduced production of antioxidants are thought to have an effect on the occurrence of cisplatin toxicity. The aim of this study was to investigate the effects of lycopene on cisplatin-induced ovarydamage, oxidative stres and histological changes in rats. Albino Wistar female rats were randomly divided into three groups. The control group (Group 1) received sunflower oil; animals in Group 2 received only cisplatin; one hour of lycopene pre-treatment was applied to the animals in Group 3 before administration of cisplatin. Cisplatin $(5 \mathrm{mg} / \mathrm{kg} /$ day $)$ was intraperitoneally injected as a single dose and lycopene $(0.5 \mathrm{mg} / \mathrm{kg} /$ day $)$ was administered by gavage. Biochemical and histopathological methods were utilised for evaluation of the oxidative ovary-damage. There was an increase in the levels of malondialdehyde, while total glutathione, glutathione reductase, and superoxide dismutase were decreased in Group 3, but it is observed that these ratios are reversed in the Group 1 and in the Group 2. Lycopene had protective effect against cisplatin-induced ovary-damaged.
\end{abstract}

Key words: Antioxidants - Cisplatin — Lipid peroxidation — Lycopene - Oxidative ovarian damage

\section{Introduction}

The anti-cancer drugs, particularly those used in reproductive period, may cause several complications such as ovarian insufficiency and infertility (Sommezer and Oktay 2004). Cisplatin (cis-diamminedichloroplatinum-II) is a widely prescribed anticancer drug. The activity against various neoplasms has been shown especially in the head and neck, testis and ovarian, bladder and small cell lung cancers. The mechanism of action of cisplatin toxicity on the ovaries is not fully described. However, further production of free oxygen radicals and reduced production of antioxidants are thought to have an effect on the occurrence of cisplatin

Corerespondence to: Nur Gozde Kulhan, Erzincan University Medical Faculty, Gynaecology and Obstetrics Department, Erzincan, Turkey

E-mail: mehmet_kulhan@yahoo.com toxicity (Weijl et al. 1998; Olas et al. 2004). Moreover, it has been demonstrated that cisplatin-associated infertility is caused by the toxic effect on the primordial follicles. Since the primordial follicles are not able to regenerate, the damage caused by the exposure to toxic agents may lead to ovarian insufficiency and infertility (Yucebilgin et al. 2004). It has been claimed that free radical-related organ damage is the result of deteriorating antioxidant defense mechanisms. Moreover, it was reported that the toxicity caused by cisplatin in the tissues was closely related to the increased lipid peroxidation (Wozniak et al. 2004). This literature knowledge suggests that antioxidant treatment might be helpful to prevent cisplatin -related ovarian toxicity and therefore infertility due to this toxicity.

Lycopene, a naturally occurring carotenoid, has attracted considerable attention as a potential chemopreventive agent. Recently, lycopene has received particular attention as a result of studies that have reported that it is a highly efficient 
antioxidant and has a singlet-oxygen and free radical scavenging capacity (Tapiero et al. 2004; Petyaev 2015). A study by Ucar et al. reported that furan-induced oxidative ovarian injury regressed with lycopene in diabetic and non-diabetic rats. (Ucar and Pandir 2017). In another study (El-Saad et al. 2016), it was found that lycopene inhibited dichlorvosinduced hepatic damage. Many studies demonstrated that lycopene has helped to eliminate the adverse efects of risk factors in the case of heart and cancer diseases (Bas and Pandir 2016; Unal et al. 2016). In literature research, we found no information about preventing oxidative ovarian damage due to cisplatin administration with lycopene in rats. Thus, the purpose of this study was to demonstrate whether lycopene would be efficacious for preventing oxidative ovarian damage due to cisplatin administration and to define the association of oxidative stress in ovarian tissues.

\section{Material and Methods}

\section{Animals}

The recommendations of the Declaration of Helsinki (1964) for animal care were taken into account. The experiments were carried out in accordance with "Principles of laboratory animal care" (NIH publication no. 86-23, revised 1985). For the experiment, a total of 18 albino Wistar female rats weighing between 250-265 g were used. Rats were provided by Atatürk University Medical Experimental Application and Research Center. The animals were kept in groups at room temperature $\left(22^{\circ} \mathrm{C}\right)$ and fed ad libitum. Animal experiments were performed in accordance with the National Guideline on the Use and Care of Laboratory Animals and approved by the local animal ethics committee of Atatürk University Erzurum, Turkey (Ethics Committee Number: 1800109520 Dated: 04.04.2018).

\section{Chemical substances}

The thiopental sodiumused in the experiment was provided by Ibrahim Etem Ulagay (Istanbul, Turkey), cisplatin was provided by Ebewe Liba-(Turkey) and lycopene was provided by Solgar (USA). Distilled water was used for dissolving cisplatin and lycopene.

\section{Experimental groups}

The rats used in this study were divided into three groups: 1) C group, control rats, 2) CisPt group, rats received cisplatin (5 mg/kg/day in 14 days) and 3) LC group, rats received $0.5 \mathrm{mg} / \mathrm{kg} /$ day lycopene plus $5 \mathrm{mg} / \mathrm{kg} /$ day cisplatin in 14 days. Lycopene was administered by oral gavage. Sunflower oil as the solvent was applied by the same method and same volume $(0.5 \mathrm{ml})$. One hour after administration of lycopene, the rats were injected with cisplatin intraperitoneally (i.p.). In the literature, the protective drugs against cisplatin toxicity are usually given to experimental animals one hour before cisplatin (Coskun et al. 2014). At the end of the period, six rats from each group were sacrificed using highdose anesthetic $(50 \mathrm{mg} / \mathrm{kg}$ of thiopental i.p.). Their ovaries were removed and oxidant and antioxidant parameters were measured to evaluate oxidative stress in the ovary-exposed tissues. The tissues were also examined histopathologically.

\section{Biochemical analysis of ovarian tissue}

Whole ovarian tissue was weighed and homogenized on ice with 2-ml relevant buffer. Buffers were $0.5 \%$ hexadecyltrimethyl ammonium bromide $(\mathrm{pH}=6)$, potassium phosphate buffer formyelophoroxidase assay, $1.15 \%$ potassium chloride solution for malondialdehyde analysis and $\mathrm{pH} 7.5$ phosphate buffer for other analyzes. It was then centrifuged at $4^{\circ} \mathrm{C}, 10,000 \mathrm{rpm}$ for $15 \mathrm{~min}$. The supernatant was used for analysis.

\section{Malondialdehyde (MDA) analysis}

The concentrations of ovarian mucosal lipid peroxidation were determined by estimating MDA using the thiobarbituric acid test (Ohkawa et al. 1979). $0.5 \mathrm{ml}$ homogenate was added to a solution containing $0.2 \mathrm{ml}$ of $80 \mathrm{~g} / \mathrm{l}$ sodium lauryl sulfate, $1.5 \mathrm{ml}$ of $200 \mathrm{~g} / \mathrm{l}$ acetic acid, $1.5 \mathrm{ml}$ of $8 \mathrm{~g} / \mathrm{l}$ of 2 -thiobarbiturate, and $0.3 \mathrm{ml}$ of distilled water. The mixture was incubated at $98^{\circ} \mathrm{C}$ for $1 \mathrm{~h}$. After cooling, $5 \mathrm{ml}$ of $\mathrm{n}$-butanol : pyridine $(15: 1)$ was added. The mixture was vortexed for $1 \mathrm{~min}$ and centrifuged at $4000 \mathrm{rpm}$ for $30 \mathrm{~min}$. The absorbance of supernatant was measured at $532 \mathrm{~nm}$. The standard curve was obtained by using 1,1,3,3-tetramethoxypropane.

\section{Total glutathione (GSH) analysis}

The amount of GSH in the total homogenate was measured according to the method of Sedlak and Lindsay with some modifications (Sedlak and Lindsay 1968). The sample was weighed and homogenized in $2 \mathrm{ml}$ of $50 \mathrm{mmol} / \mathrm{l}$ Tris- $\mathrm{HCl}$ buffer containing $20 \mathrm{mmol} / \mathrm{l} \mathrm{EDTA}$ and $0.2 \mathrm{mmol} / \mathrm{l}$ sucrose at $\mathrm{pH}$ 7.5. The homogenate was immediately precipitated with $0.1 \mathrm{ml}$ of $25 \%$ trichloroacetic acid and the precipitate was removed after centrifugation at $4200 \mathrm{rpm}$ for 40 minutes at $4^{\circ} \mathrm{C}$ and the supernatant was used to determine GSH level. A total of $1500 \mu \mathrm{l}$ of measurement buffer $(200 \mathrm{mmol} / \mathrm{l}$ Tris$\mathrm{HCl}$ buffer containing $0.2 \mathrm{mmol} / \mathrm{l} \mathrm{EDTA}$ at $\mathrm{pH} 7.5), 500 \mu \mathrm{l}$ of supernatant, $100 \mu \mathrm{l}$ of DTNB $(10 \mathrm{mmol} / \mathrm{l})$ and $7900 \mu \mathrm{l}$ of methanol were added into a tube and vortexed and incubated at $37^{\circ} \mathrm{C}$ for 30 minutes. 5,5-Dithiobis (2-nitrobenzoic acid) (DTNB) was used as an chromogen and it formed a yellow- 
Table 1. Effect of cisplatine (CisPt) or its combination with lycopene (LC) on levels of ovary MDA, GSH, GR and SOD activities in rats

\begin{tabular}{lcccc}
\hline Group & MDA $(\mu \mathrm{mol} / \mathrm{g})$ & GSH $(\mathrm{nmol} / \mathrm{g})$ & GR $(\mathrm{u} / \mathrm{g})$ & SOD $(\mathrm{u} / \mathrm{g})$ \\
\hline C & $5.583 \pm 0.7574$ & $5.350 \pm 0.5010$ & $6.150 \pm 0.3834$ & $9.550 \pm 0.3271$ \\
CisPt & $15.5 \pm 1.8708^{\mathrm{a}}$ & $1.533 \pm 0.2066^{\mathrm{b}}$ & $2.15 \pm 0.3391^{\mathrm{c}}$ & $4.717 \pm 0.6113^{\mathrm{d}}$ \\
LC & $6.4 \pm 0.5762$ & $4.35 \pm 0.4806$ & $5.333 \pm 0.5715$ & $8.917 \pm 0.3312$ \\
\hline
\end{tabular}

Data are mean \pm SD. ${ }^{\mathrm{a}} p=0.784,{ }^{\mathrm{b}} p=0.003,{ }^{\mathrm{c}} p=0.018,{ }^{\mathrm{d}} p=0.078 v$ s. corresponding value of $\mathrm{C}$ group. $\mathrm{MDA}$, malondialdehyde; GSH, total glutathione; GR, glutathione reductase; SOD, superoxide dismutase; C, control.

colored complex with sulfhydry groups. The absorbance was measured at $412 \mathrm{~nm}$ using a spectrophotometer (Beckman DU 500, USA). The standard curve was obtained using reduced glutathione.

\section{Glutathione reductase (GR) analysis}

GR activity was determined spectrophotometrically by measuring the rate of NADPH oxidation at $340 \mathrm{~nm}$ according to Carlberg and Mannervik method (Carlberg and Mannervik 1985). After tissue homogenization, supernatant was used for GR measurement. After the NADPH and GSSG addition, chronometer was on and absorbance was measured for $5 \mathrm{~min}$ by $30-\mathrm{min}$ intervals at $340 \mathrm{~nm}$ spectrophotometric methods.

\section{Superoxide dismutase (SOD) analysis}

Measurements were performed according to the method of Sun et al (1988). When xanthine is converted into uric acid by xanthine oxidase, SOD forms. Providing that the nitro blue tetrazolium (NBT) is added to this reaction, SOD reacts with NBT and a purple formazan dye is formed. The sample was weighed and homogenized in $2 \mathrm{ml}$ of $20 \mathrm{mmol} / \mathrm{l}$ phosphate buffer containing $10 \mathrm{mmol} / \mathrm{l}$ of EDTA at $\mathrm{pH} 7.8$. The sample was centrifuged at $6000 \mathrm{rpm}$ for 10 minutes and than the brilliant supernatant was used as assay sample.

\section{Histological examination}

All samples in each group were evaluated histologically. Histological examination was performed at the pathology department of University Hospital. Following dehydration of the excised ovaries and embedment in paraffin blocks, 4-6 mm slices were prepared and stained with hematoxylin and eosin. The specimens were evaluated under light microscopy; primary, secondary and antral follicle-containing ovarian tissue was considered normal ovary structure. Ovarian damage, including follicular cell degeneration, vascular congestion, hemorrhage, and inflammation (neutrophil infiltration), was evaluated histologically

\section{Statistical analysis}

The software SPSS 16.0 was employed for the statistical analysis (SPSS Inc., Chicago, IL). Differences among the three groups were evaluated with Tuckey analysis. $p<0.05$ was considered as statistically significant.

\section{Results}

Effect of cisplatin or its combination with lycopene on levels of ovary MDA, GSH, GR and SOD activities in rats are presented in Table 1. As the results of our study demonstrated, in ovarian tissues of animals administered cisplatin, an increase in the levels of MDA was observed, while levels of GSH, GR, and SOD activities were decreased, but these ratios are reversed in the $\mathrm{C}$ and in the LC groups (Figure 1).

Evaluation of histological ovarian damage results is shown in Figure 2. The ovarian tissue of rats from the $\mathrm{C}$ group showed normal ovarian architecture with an orderly arrange-

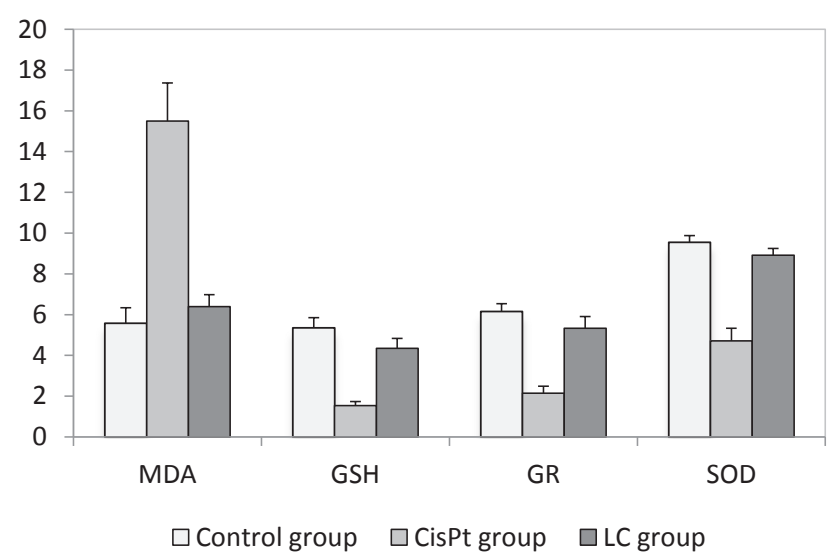

Figure 1. Malondialdehyde (MDA), total glutathione (GSH), glutathione reductase (GR), and superoxide dismutase (SOD) levels between groups. Data are mean $\pm \mathrm{SD} .{ }^{\mathrm{a}} p=0.784,{ }^{\mathrm{b}} p=0.003$, ${ }^{c} p=0.018,{ }^{d} p=0.078 v s$. corresponding value of $\mathrm{C}$ group. CisPt, cisplatin; LC, lycopene. 

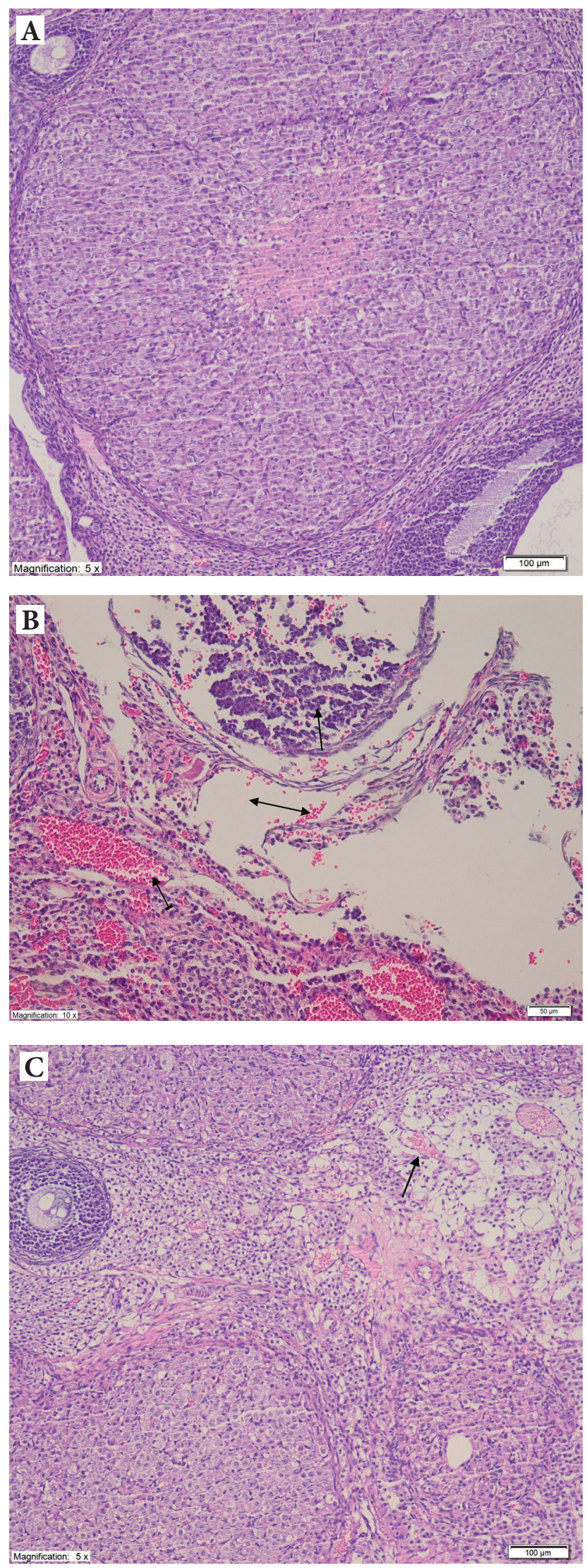

ment of follicles (Figure 2A). The ovarian tissue of animals treated with cisplatin (CisPt group) exhibited disordered, apoptotic cells with shrunken pyknotic nuclei, hemorrhage and vascular congestion as well as follicular degeneration and edema compared to the $\mathrm{C}$ group (Figure 2B). Animals treated with lycopene before cisplatin administration (LC group) showed improved histological architecture and orderly arrangement (Figure 2C).

\section{Discussion}

Every year, thousands of women undergo chemotherapy, and some face decreased fertility ranging from minimal to complete ovarian failure. cisplatin is used in the treatment of many solid tumors, mainly testicular and ovarian tumors. However, it was reported that cisplatin caused severe adverse effects such as nephrotoxicity, neurotoxicity, gastric toxicity, and infertility (Pogach et al. 1989). It was shown that chemotherapeutic medicines leading to either temporary or permanent infertility severely affected the ovaries and hormonal balance (DeVita et al. 2005). Limited studies have shown that cisplatin damages primordial follicles, which constitute a major part of the ovarian reserve. The number of primordial follicles is positively correlated with reproductive proficiency in female mammals (Yucebilgin et al. 2004). Meirow et al. examined human ovaries that had been exposed to cisplatin, and histologically identified apoptosis in granulosa cells and the destruction of primordial follicles (Meirow 2000). Antioxidants reduce reactive oxygen radical-induced oocyte and follicular damage. Bas and Pandir (Bas and Pandır 2016) have shown that furan induced lung toxicity in the diabetic rats with severe pathological alterations. Emphysematous changes, hemorrhage, changes in connective tissue of the alveolar septa, edema, and desquamation of the epithelial cell of the terminal bronchiole were observed in the diabetic furan group. Lycopene treatment cured these transfo Pogach rmations. Emphysematous and hemorrhage were seen in the diabetic furan + lycopene group in moderate level (Unal et al. 2016 ). They demonstrated that histological damages of kidney were more severe in diabetic furan group, particularly extensive infammatory cell infltration, glomerular lobulation,

Figure 2. Histological ovarian damage. A. Normal histopathologic appearance is observed in overgrowth of healthy control group (H\&E, 100× magnification). B. The destructive secondary follicle (straight arrow), dilate congestige blood vessel (striated arrow), hemorrhage and edema (bilateral arrow) are observed in the CisPt group treated with cisplatin alone (H\&E, 200× magnification). C. Normal appearance is observed except for the congestige blood vessel (straight arrow) in LC group (H\&E, 100× magnification). For abbreviations, see Fig. 1. 
glomerular atrophy, tubular degeneration, hemorrhage, and dilatation of Bowmann's space. Lycopene supplementation was protective against furan caused histopathological changes, too. Administration of cisplatin increased severe hemorrhage, edema, follicular degeneration, and vascular congestion in the ovary tissue in this study. However, milder pathological changes were seen in lycopene + cisplatin group. In this way, the toxicity caused by cisplatin in rat ovarian tissues appears to be inhibited by lycopene.

In chemotherapy-induced ovarian damage, the effects of protective drugs are evaluated by measuring plasma levels of antioxidants and reactive oxygen radicals and follicle morphology. As the results of our study demonstrated, in ovarian tissues of animals administered cisplatin, there was an increase in the levels of MDA, which is oxidant parameter, while the levels of antioxidants such as GSH, GR, and SOD were decreased. (Figure 1).

MDA is the end-product of lipid peroxidation. Lipid peroxidation is known to be the most harmful effect of free radicals in the cell (Girotti 1998). It was reported that cisplatin caused oxidative damage in the ovarian tissue increasing MDA concentration and decreasing GSH concentration (Girotti 1998). In our study, for ovarian tissues of the animals in CisPt group, there was an increase in the levels of MDA. On the other hand, it was clearly seen that this increase observed in the CisPt group was not observed in the LC and C groups $(15.5 \pm 1.8708 \mu \mathrm{mol} / \mathrm{g}, 6.4 \pm 0.5762 \mu \mathrm{mol} / \mathrm{g}, 5.583$ $\pm 0.7575 \mu \mathrm{mol} / \mathrm{g}$, respectively).

GSH is a non enzymatic endogenous antioxidant parameter. Under physiological conditions, the oxidant/antioxidant balance is maintained with predominance of antioxidants. Degradation of this balance causes tissue damage called oxidative stress. Therefore, oxidant/antioxidant balance is used to assess if tissue damage emerges (Dayangan Sayan et al. 2018). GSH protects the cells against oxidative damage, keeping the $-\mathrm{SH}$ groups of proteins reduced and preventing them from reacting with free radicals (Urso and Clarkson 2003). In the ovaries of the rats given only cisplatin, GSH level was decreased in comparison with the LC and C group. $(1.533 \pm 0.2066 \mathrm{nmol} / \mathrm{g}, 4.350 \pm 0.4806 \mathrm{nmol} / \mathrm{g}, 5.350$ $\pm 0.5010 \mathrm{nmol} / \mathrm{g}$, respectively).

The most important goal of the reaction catalyzed by the enzyme GR is to maintain the reduced glutathione/oxidized glutathione ratio in the cell medium. Oxidative stress occurs when this ratio is reduced (Urso and Clarkson 2003). In this study, GR level was found to be lower in CisPt group compared with LC and C group $(2.150 \pm 0.3391 \mathrm{u} / \mathrm{g}, 5.333$ $\pm 0.5715 \mathrm{u} / \mathrm{g}, 6.150 \pm 0.3834 \mathrm{u} / \mathrm{g}$, respectively).

SOD, another protective enzyme against free oxygen radicals, catalyzes the transformation of superoxide molecule into hydrogen peroxide and molecular oxygen (Nordberg and Arner 2001). Low SOD activity found in ovarian tissues of rats given cisplatin alone in comparison with the LC and C group $(4.717 \pm 0.6113 \mathrm{u} / \mathrm{g}, 8.917 \pm 0.3312 \mathrm{u} / \mathrm{g}, 9.55$ $\pm 0.3271 \mathrm{u} / \mathrm{g}$, respectively).

It has been shown that lycopene has the highest antioxidant activity among carotenoids against hydrogen peroxide and nitrogen dioxide radicals (Czeczuga-Semeniuk et al. 2009). In addition, lycopene has been reported to attenuate oxidative stress and exert anticancer effects both in vitro and in vivo (Czeczuga-Semeniuk et al. 2009). The main antioxidant feature depends on upregulating antioxidant systems in the cell, and it also has a direct destructive effect on free radicals. During ${ }^{1} \mathrm{O}_{2}$ quenching (oxygen ${ }^{1} \mathrm{O}_{2}$ quenchers), the energy is converted from ${ }^{1} \mathrm{O}_{2}$ to the lycopene molecule into an energyrich triplet state. In contrast, capture of other reactive oxygen species (ROSs) such as hydroxyl radical (OHs), Nitronium $\left(\mathrm{NO}_{2}{ }^{+}\right)$or peroxynitrite leads to oxidative degradation of the lycopene molecule. Thus, lycopene may protect in vivo against oxidation of lipids, proteins and DNA (Czeczuga-Semeniuk et al. 2009). In the present investigation, pre-treatment with lycopene inhibited the increase in MDA induced by cisplatin in ovary, but activated the increase the levels of antioxidants such as GSH, GR, and SOD.

There are some limitations of our study. First, the results of experimental studies on laboratory animals may not be extrapolated to humans. Thus, our study needs to be verified in future studies in humans. In addition, our results can be verified by more ovarian-toxic agent, namely alkylating agents that destroys primordial follicle pool. For example, cyclophosphamide can be chosen for future studies instead of cisplatin that is moderately gonadotoxic.

\section{Conclusion}

It was shown that cisplatin treatment induced ovary damage and especially pre-treatment with lycopene provided protective effect against this cisplatin-induced ovarian damage. But, before a conclusive statement on potential usefulness of lycopene as adjunct to the cisplatin therapy there is a need for further studies including human trials.

Conflict of interest. The authors declare that they have no conflict of interest. All procedures followed were in accordance with the ethical standards of the responsible committee on human experimentation (institutional and national) and with the Helsinki Declaration of 1975, as revised in 2008.

\section{References}

Bas H, Pandir D (2016): Protective efects of lycopene on furantreated diabetic and non-diabetic rat lung. Biomed. Environ. Sci. 29, 143-147

Carlberg I, Mannervik B (1985): Glutathione reductase. Methods Enzymol. 113, 484-490 
https://doi.org/10.1016/S0076-6879(85)13062-4

Chu E, Devita VT, Jr (2005): Principles of cancer management: chemotherapy. In: Cancer: Principals and Practice of Oncology (Eds. VT Devita, S Hellman, SA Rosenberg), pp. 224-235, Lippincott Williams \& Wilkins. Philadelphia, USA

Coskun R, Turan MI, Turan IS, Gulapoglu M (2014): The protective effect of thiamine pyrophosphate, but not thiamine, against cardiotoxicity induced with cisplatin in rats. Drug Chem. Toxicol. 37, 290-294 https://doi.org/10.3109/01480545.2013.851688

Czeczuga-Semeniuk E, Jarzabek K, Lemancewicz D, Wołczyński S (2009): The vitamin A family can significantly decrease the expression of ERbeta of ERs positive breast cancer cells in the presence or absence of ER ligands and paclitaxel. Gynecol. Endocrinol. 25, 287-293 https://doi.org/10.1080/09513590802530924

Dayangan Sayan C, Tulmac OB, Karaca G, Ozkan ZS, Yalcin S, Devrim T, Dindar Badem N (2018): Could erythropoietin reduce the ovarian damage of cisplatin in female rats? Gynecol. Endocrinol. 34, 309-313 https://doi.org/10.1080/09513590.2017.1395836

El-Saad AA, Ibrahim MM, Hazani AA, El-Gaaly GA (2016): Lycopene attenuates dichlorvos-induced oxidative damage and hepatotoxicity in rats. Hum. Exp. Toxicol. Jun. 35, 654-665 https://doi.org/10.1177/0960327115597981

Girotti AW (1998): Lipid hydroperoxide generation, turnover, and effector action in biological systems. J. Lipid Res. 39, 1529-1542

Meirow D (2000): Reproduction post chemotherapy in young cancer patients. Mol. Cell Endocrinol. 27, 123-131 https://doi.org/10.1016/S0303-7207(00)00365-8

Nordberg J, Arner ESJ (2001): Reactive oxygen species, antioxidants, and the mammalian thioredoxin system. Free Radic. Biol. Med. 31, 1287-1312 https://doi.org/10.1016/S0891-5849(01)00724-9

Ohkawa H, Ohishi N, Yagi K (1979): Assay for lipid peroxides in animal tissues by thiobarbituric acid reaction. Anal. Biochem. 95, 351-358 https://doi.org/10.1016/0003-2697(79)90738-3

Olas B, Wachowicz B (2004): Resveratrol reduces oxidative stress induced by platinum compounds in blood platelets. Gen. Physiol. Biophys. 23, 315-326

Petyaev IM (2015): Improvement of hepatic bioavailability as a new step for the future of statin. Arch. Med. Sci. 25, 406-410 https://doi.org/10.5114/aoms.2015.50972
Pogach LM, Lee Y, Gould S, Giglio W, Meyenhofer M, Huang HFS (1989): Characterization of cis-platinum-induced Sertoli cell dysfunction in rodents. Toxicol. Appl. Pharmacol. 98, 350-361 https://doi.org/10.1016/0041-008X(89)90239-1

Sedlak J, Lindsay RH (1968): Estimation of total, protein-bound, and nonprotein sulfhydryl groups in tissue with Ellman's reagent. Anal Biochem. 24, 192-205

https://doi.org/10.1016/0003-2697(68)90092-4

Sonmezer M, Oktay K (2004): Fertility preservation in female patients. Hum. Reprod. Update. 10, 251-266 https://doi.org/10.1093/humupd/dmh021

Sun Y, Oberley LW, Li Y (1988): A simple method for clinical assay of superoxide dismutase. Clin Chem. 34, 497-500

Tapiero H., Townsend DM, Tew KD (2004): The role of carotenoids in the prevention of human pathologies. Biomed. Pharmacother. 58, 100-110 https://doi.org/10.1016/j.biopha.2003.12.006

Uçar S, Pandir D (2017): Furan induced ovarian damage in nondiabetic and diabetic rats and cellular protective role of lycopene. Arch. Gynecol. Obstet. 296, 1027-1037 https://doi.org/10.1007/s00404-017-4521-7

Unal B, Pandir D, Bas H (2016): Lycopene protects the diabetic rat kidney against oxidative stress-mediated oxidative damage induced by furan. Braz. Arc. Biol. Technol. 59, e16150794 https://doi.org/10.1590/1678-4324-2016150794

Weijl NI, Hopman GD, Wipkink-Bakker A, Lentjes EG, Berger HM, Cleton FJ, Osanto S (1998): Cisplatin combination chemotherapy induces a fall in plasma antioxidants of cancer patients. Ann. Oncol. 9, 1331-1337 https://doi.org/10.1023/A:1008407014084

Wozniak K, Czechowska A, Blasiak J (2004): Cisplatin-evoked DNA fragmentation in normal and cancer cells and its modulation by free radical scavengers and the tyrosine kinase inhibitor STI571. Chem. Biol. Interact. 15, 309-318 https://doi.org/10.1016/j.cbi.2004.03.001

Yucebilgin MS, Terek MC, Ozsaran A, Akercan F, Zekioglu O, Isik E, Erhan Y (2004): Effect of chemotherapy on primordial follicular reserve of rat: an animal model of premature ovarian failure and infertility. Aust. N. Z. J. Obstet. Gynaecol. 44, 6-9 https://doi.org/10.1111/j.1479-828X.2004.00143.x

Received: December 4, 2018

Final version accepted: January 28, 2019

First published online: February 26, 2019 